Original Article

\title{
ANTIOXIDANT STUDIES ON METHANOL AND AQUEOUS EXTRACTS OF GYMNOSPORIA MONTANA PLANT
}

\author{
NISHAT ANSARI, DIVYA CHANDEL
}

Department of Zoology, BMT and Human Genetics, School of Sciences, Gujarat University, Navrangpura 380009, Ahmedabad, India Email: divya_chandel@yahoo.com

Received: 20 Nov 2018 Revised and Accepted: 20 Dec 2018

\section{ABSTRACT}

Objective: The main objective of this study was to evaluate the free radical scavenging activity of methanol (70\%) and aqueous extract of $G$. montana leaves which is a traditionally used herb known for its hepatoprotective activity.

Methods: The in vitro antioxidant activity of G. montana extract was determined using 1, 1-diphenyl-2-picrylhydrazyl radical (DPPH), 2,2'-azinobis(3-ethylbenzothiaziline-6-sulfonate (ABTS), Hydrogen peroxide scavenging activity, Superoxide anion radical scavenging activity and Reducing Power ability at three different concentrations $(1.78 \mu \mathrm{g} / \mathrm{ml}, 3.57 \mu \mathrm{g} / \mathrm{ml}$ and $7.14 \mu \mathrm{g} / \mathrm{ml})$

Results: The Results revealed similar observations between the methanol and aqueous extract with respect to standard and showed potent antioxidant activity. Ascorbic acid was used as a standard, which showed IC 50 value $4.71 \mu \mathrm{g} / \mathrm{ml}$, whereas, methanol and aqueous extract showed 5.08 $\mu \mathrm{g} / \mathrm{ml}$ and $5.69 \mu \mathrm{g} / \mathrm{ml}$. Three different concentrations were used which showed a dose-dependent non-significant increase in percent inhibition.

Conclusion: Findings indicate that this plant is a good source of antioxidant and can be used for the treatment of diseases as such medicinal plant extracts are natural products and they are comparatively safe, eco-friendly, less expensive and locally available. Hence, the validation of the effects of these herbal remedies will have to be undertaken for their wider acceptance.

Keywords: Gymnosporia montana, Antioxidants, Medicinal plants, DPPH, ABTS, Scavenging

(C) 2019 The Authors. Published by Innovare Academic Sciences Pvt Ltd. This is an open access article under the CC BY license (http://creativecommons.org/licenses/by/4.0/) DOI: http://dx.doi.org/10.22159/ijpps.2019v11i2.30883

\section{INTRODUCTION}

Biological combustion involved in various processes produces reactive oxygen species or free radicals, which, if excess in living beings can cause various problems like asthma, cancer, cardiovascular diseases, liver diseases, muscular degeneration and other inflammatory processes [1] resulting in oxidative stress. Oxidative stress is an imbalance between oxidants and antioxidants and causes damage in all types of biomolecules including protein nucleic acid, DNA, and RNA [2]. Hence, the balance between free radicals and antioxidants is believed to be a critical concept for maintaining a good biological system. Antioxidants act as free radical scavengers, reducing agents, quenchers of the singlet oxygen molecule and activators for the antioxidative enzyme to suppress the damage induced by free radicals in the biological system. It has been found that there is an inverse association between the mortality from age-related diseases and the consumption of plant products [3]. Nahak and Sahu (2011) reported that the ethanol extract of $P$. cubeba had a higher antioxidant activity than both methanol and aqueous extracts and was also higher than an ethanol extract of $P$. nigrum [4]. Phenolic compounds, such as phenolic acids, flavonoids, quinones, coumarins, lignans, stilbenes, and tannins, are rich in antioxidant properties $[5,6]$. These antioxidant compounds possess anti-inflammatory, anti-atherosclerotic, anti-tumor, antimutagenic, anti-carcinogenic, anti-bacterial and anti-viral activities [6-8]. In addition, Cai and co-workers reported that the total phenolic content of Chinese medicinal plants showed a positive significant linear relationship with antioxidant activity [9].

There are about 2,50,000 higher plant species available on earth, out of which more than 80,000 are medicinal [10]. Plants had been used as traditional health care system for the centuries and are a major source of the therapeutic agents for curing the human diseases. In the last few years, more than 13,000 plants have been studied for the various diseases among these some medicinal properties of plants have been documented by researchers [11]. The study was done on medicinal plants and vegetables, strongly support the idea that plant constituents with antioxidant activity are capable of exerting protective effects against oxidative stress in biological systems [12]. Plants are a rich source of free radical scavenging molecules such as vitamins, terpenoids, phenolic acids, lignins, tannins, flavanoids, quinones, coumarins, alkaloids, amines, betalains and other metabolites which are rich in antioxidant activity [13]. The antioxidants present in plant products help in the stimulation of cellular defense system and biological system against oxidative damage. Recently, much attention has been directed towards ethnomedicine with strong antioxidant properties and low cytotoxicity. Numerous plants with therapeutic value are used in these traditional practices of medicine.

Several assays have indicated the involvement of certain factors that are intrinsic components of the extracts, ranging from specific compounds like ascorbic acid to vegetable fibers which could act as nonspecific redox agents, free radical scavengers or ligands for binding metals or toxic principles [14].

Taking into consideration the vast potentiality of plants as sources for antioxidants, a systematic investigation was undertaken to screen the local flora for its radical scavenging activity and G. montana was finalized for further investigations. G. montana, a plant of Celastraceous family, is used in different regions of India as a traditional herb, especially for its hepatoprotective activity, and leaves of this plant are chewed to cure jaundice. G. montana is distributed throughout the arid, dry areas of India like Punjab and Gujarat and in other countries like Afghanistan, Arabia, Mediterranean, Tropical Africa, Malaya and Australia [15]. The leaf, flower and fruit extract exhibited antimicrobial and radical scavenging activity. The observed bio-efficacies of the plant could be ascribed to the presence of bioactive principles in the extracts. The plant in its suitable form can be used to prevent and control/treat microbial infections and oxidative damage [16]. Taking into consideration the vast potentiality of plant Gymnosporia montana, two different leaf extracts $(70 \%$ methanol and aqueous) were investigated as sources for antioxidants and ROS scavenging capacity at different concentrations. 


\section{MATERIALS AND METHODS}

\section{Collection of plant materials}

The leaves of G. montana were collected from a Nursery in sector-30 of Gandhinagar, Gujarat. The taxonomic identity was authenticated and herbarium sheet with reference No. PH/14/0010 was deposited in Department of Pharmacognocy, K. B. Institute of Pharmaceutical Education and Research, Gandhinagar, India.

\section{Preparation of extracts}

Extracts were prepared by the method of Dhru et al. (2011) with few modifications. The leaves of G. montana were air-dried and powdered. $20 \mathrm{gm}$ of the powder was taken with $100 \mathrm{ml}$ of $70 \%$ methanol to prepare methanolic extract and $100 \mathrm{ml}$ of distilled water to prepare an aqueous extract [17]. This was mixed in a closed flask for $24 \mathrm{~h}$ using a magnetic stirrer. Then it was filtered with filter paper and the filtrate was evaporated to dryness in an incubator at $60{ }^{\circ} \mathrm{C}$. After drying, the weight of the water-soluble extractive value was obtained by calculating the difference in weight between powdered dried material and the weight after the extraction process. This value was expressed in percentage and the final extract was used for further investigation. After performing MTT and Mitotic Indices experiments in the laboratory, the three different concentrations; Low dose $(1.78 \mu \mathrm{g} / \mathrm{ml})$, Mid dose $(3.57$ $\mu \mathrm{g} / \mathrm{ml})$ and High dose $(7.142 \mu \mathrm{g} / \mathrm{ml})$ were finalized for the study. Both methanolic and aqueous extracts have analyzed at these concentrations for their antioxidant activity using different parameters as mentioned below. All the tests were performed three times and the mean was taken to analyze the data.

\section{Chemicals and reagents}

2,2 diphenyl 1 picrylhydrazyl (DPPH) and 2, 2'-and-bis (3ethylbenzthiazoline-6-sulphonic (ABTS) was obtained from SigmaAldrich. Naphthylethylenediamine dihydrochloride (NADPH), Phenazine methosulfate (PMS), Nicotinamide adenine dinucleotide (NADH), Nitro blue tetrazolium (NBT) were obtained from Hi-Media Laboratories Pvt. Ltd., Mumbai, India. Potassium ferricyanide, Trichloroacetic acid (TCA), Hydrogen peroxide $\left(\mathrm{H}_{2} \mathrm{O}_{2}\right)$, phosphate buffer, Ammonium persulfate, Phosphate buffer (PBS) and Ascorbic acid were obtained from Merck specialties private limited, Mumbai, India. All the chemicals and reagents were of analytical grade.

\section{DPPH radical scavenging assay}

The inhibition effects of the extract on a free radical DPPH were studied using the DPPH radical-scavenging method as described by Goze et al. (2009) with slight modifications [18]. $2 \mathrm{ml}$ of different concentrations $(1.78 \mu \mathrm{g} / \mathrm{ml}, 3.57 \mu \mathrm{g} / \mathrm{ml}$ and $7.142 \mu \mathrm{g} / \mathrm{ml})$ of the plant extract mixed with $2 \mathrm{ml}$ of DPPH solution, shaken vigorously and allowed to stand for 30 min before measuring the absorbance with a UV spectrophotometer at $517 \mathrm{~nm}$. Ascorbic acid was used as a positive control. The inhibition effects of the extract on free radical DPPH were expressed as follows:

$$
\% \text { Inhibition }=\frac{\text { Control OD }- \text { Test OD }}{\text { Control OD }} \times 100
$$

\section{ABTS radical scavenging assay}

To determine the ABTS radical scavenging assay, the method of Re $e t$ al. (1999) was adopted with slight modifications [19]. ABTS radical cation (ABTS) was produced by reacting ABTS $(7 \mathrm{mmol})$ with ammonium persulfate solutions $(2.4 \mathrm{mmol})$ and the mixture was allowed to stand in dark to react for $12-16 \mathrm{~h}$ at room temperature before use. For the study, $0.5 \mathrm{ml}$ sample of different concentrations $(1.78 \mu \mathrm{g} / \mathrm{ml}, 3.57 \mu \mathrm{g} / \mathrm{ml}$ and $7.142 \mu \mathrm{g} / \mathrm{ml})$ of methanol and aqueous extract was added to $0.3 \mathrm{ml}$ of ABTS solution and the final volume was made up of $1 \mathrm{ml}$ with ethanol. The absorbance was read at 734 $\mathrm{nm}$. Control was prepared as above without any extracts. The percentage of ABTS scavenging activity was calculated by using the formula as given below:

$$
\% \text { ABTS scavenging activity }=\frac{\text { Control OD }- \text { Test OD }}{\text { Control OD }} \times 100
$$

\section{$\mathrm{H}_{2} \mathrm{O}_{2}$ scavenging activity}

Scavenging activity of hydrogen peroxide by the plant extract was estimated using the method of Ruch et al. (1989) with little modification [20]. $4 \mathrm{mmol} / \mathrm{l}$ solutions of $\mathrm{H}_{2} \mathrm{O}_{2}$ were prepared in PBS (pH 7.4). The Plant extract of various concentrations of methanol and aqueous extract was mixed with $0.6 \mathrm{ml}$ of $4 \mathrm{mmol} / \mathrm{l} \mathrm{H}_{2} \mathrm{O}_{2}$ solution prepared in PBS and incubated for $10 \mathrm{~min}$. The absorbance of the solution was taken at $230 \mathrm{~nm}$ against a blank solution containing the plant extract in PBS without $\mathrm{H}_{2} \mathrm{O}_{2}$. Ascorbic acid was used as positive control. The amount of hydrogen peroxide radical inhibited by the extract was calculated using the following equation:

$$
\begin{aligned}
& \% \text { Hydrogen peroxide scavenging activity } \\
& =\frac{\text { Control OD }- \text { Test OD }}{\text { Control OD }} \text { X } 100
\end{aligned}
$$

\section{Superoxide anion radical scavenging activity}

This activity was measured by the reduction of NBT according to a previously reported method of Fontana et al. (2001) with slight modifications [21]. The nonenzymatic phenazine methosulfatenicotinamide adenine dinucleotide (PMS/NADH) system generates superoxide radicals, which reduce Nitro blue tetrazolium (NBT) to a purple formazan. The $1 \mathrm{ml}$ reaction mixture contained phosphate buffer $(20 \mathrm{mmol}, \mathrm{pH} 7.4)$, NADH $(73 \mu \mathrm{mol})$, NBT $(50 \mathrm{~mol})$, PMS (15 $\mu \mathrm{mol}$ ) and various concentrations of the sample solution. After incubation for $5 \mathrm{~min}$ at ambient temperature, the absorbance at 562 $\mathrm{nm}$ was measured against an appropriate blank to determine the quantity of formazan generated.

$$
\begin{aligned}
& \% \text { Superoxide anion radical scavenging activity } \\
& \qquad=\frac{\text { Control OD }- \text { Test OD }}{\text { Control OD }} \times 100
\end{aligned}
$$

\section{Reducing power assay}

The reducing power of the leaf extracts was determined according to the method of Oyaizu (1986) [22]. Different concentrations of the extract were added to $2.5 \mathrm{ml}$ of phosphate buffer and $2.5 \mathrm{ml}$ of $1 \%$ potassium ferricyanide. The reaction mixture was incubated for 20 min at $50^{\circ} \mathrm{C}$, and after that $2.5 \mathrm{ml}$ of $10 \%$ TCA was added and centrifuged. The supernatant was mixed with $2.5 \mathrm{ml}$ of distilled water and $0.5 \mathrm{ml} \mathrm{of} \mathrm{FeCl}_{3}$, and the absorbance was read at $700 \mathrm{~nm}$. The assay was carried out in triplicates. Increase in absorbance of the sample with concentrations indicates the high reducing potential of the samples.

$$
\% \text { Reducing power ability }=\frac{\text { Test OD }- \text { Control OD }}{\text { Test OD }} \times 100
$$

\section{Statistical analysis}

Data are expressed as the mean $\pm S E$ and statistical significance was analyzed using a one-way analysis of variance (ANOVA) followed by Tukey's Range Test in Graph pad prism7 at the $\mathrm{p}<0.01$ significance level. The means of three replicates $(n=3)$ have been reported.

\section{RESULTS}

\section{DPPH radical scavenging assay}

The result of DPPH scavenging activity in the present study indicates that the plant is potentially active. The antioxidant capacity is also expressed as $50 \%$ inhibitory concentration $\left(\mathrm{IC}_{50}\right)$. The methanolic extract of G. montana ( $\mathrm{IC}_{50}$ value $5.08 \mu \mathrm{g} / \mathrm{ml}$ ) exhibited little stronger scavenging efficacy than aqueous leaf extract ( $\mathrm{IC}_{50}$ value $5.69 \mu \mathrm{g} / \mathrm{ml}$ ) and ascorbic acid ( $\mathrm{IC}_{50}$ value $4.71 \mu \mathrm{g} / \mathrm{ml}$ ) was used as a standard as shown in fig. 1. At a lower concentration $(1.78 \mu \mathrm{g} / \mathrm{ml})$, methanol extract showed percentage inhibition of $12.87 \%$, aqueous extract showed $12.51 \%$ and ascorbic acid showed $18.12 \%$. At mid dose $(3.57 \mu \mathrm{g} / \mathrm{ml})$, methanol extract showed $36.14 \%$, aqueous extract showed $26.59 \%$ and ascorbic acid showed $41.12 \%$ of percentage inhibition. At high dose $(7.14 \mu \mathrm{g} / \mathrm{ml})$, methanol extract showed $71.19 \%$, aqueous extract showed $65.08 \%$ and ascorbic acid showed $73.61 \%$ of percentage inhibition (fig. 1). The in vitro antioxidant assay performed on the plant extract of methanol and aqueous extract revealed non-significant antioxidant potential when compared with ascorbic acid as standard. 


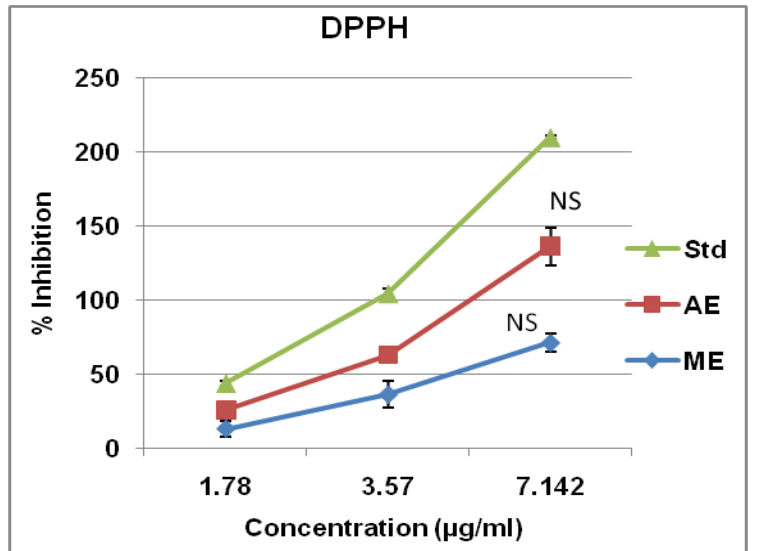

Fig. 1: 2,2-diphenyl-1-picrylhydrazyl radical scavenging activity of methanol extract (ME) and aqueous extract (AE) of $G$. montana in comparison with ascorbic acid (STD). Each value is represented as mean $\pm S E, n=3$ )

\section{ABTS radical scavenging assay}

The methanol and aqueous leaf extract of G. montana were effective scavengers of the ABTS radical and this activity was comparable to ascorbic acid. Methanol and aqueous extract exhibited potent scavenging effects against ABTS. Fig. 2 shows that at lower concentration $(1.78 \mu \mathrm{g} / \mathrm{ml})$, methanol extract showed percentage inhibition of $23.85 \%$, aqueous extract showed $18.76 \%$ and ascorbic acid showed $28.43 \%$. At mid dose $(3.57 \mu \mathrm{g} / \mathrm{ml})$, methanol extract showed $29.52 \%$, aqueous extract showed $30.62 \%$ and ascorbic acid showed $43.69 \%$ of percentage inhibition. At high dose $(7.14 \mu \mathrm{g} / \mathrm{ml})$ methanol extract showed $42.14 \%$, aqueous extract showed $45.98 \%$ and ascorbic acid showed $56.03 \%$ of percentage inhibition. Data showed a non-significant increase in the percentage inhibition when all the different concentrations of both the extracts were compared with the standard.

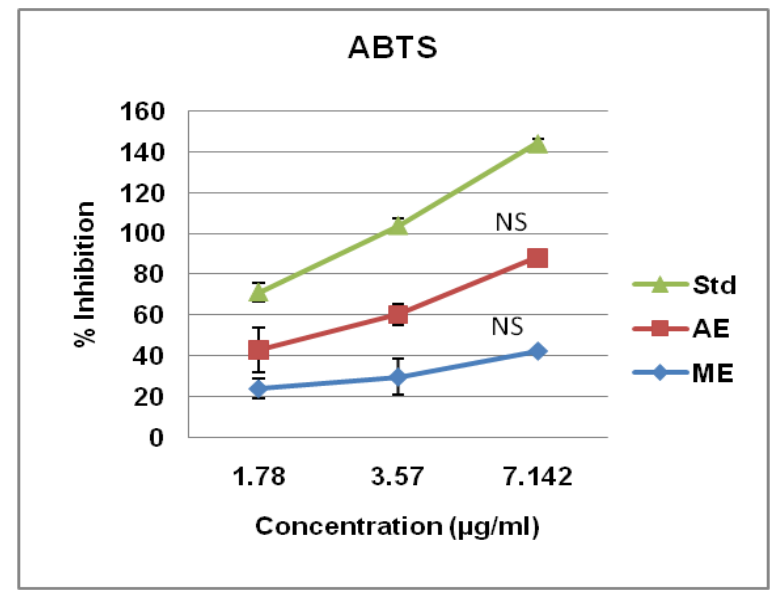

Fig. 2: 2, 2'-azino-bis (3-ethylbenzthiazoline-6-sulphonic) radical scavenging activity of methanol extract (ME) and aqueous extract (AE) of $G$. montana in comparison with ascorbic acid (STD). Each value is represented as mean $\pm S E, n=3$ )

\section{$\mathrm{H}_{2} \mathrm{O}_{2}$ radical scavenging assay}

As shown in fig. 3, both the extracts of G. montana also demonstrated hydrogen peroxide decomposition activity in a concentrationdependent manner with percentage inhibition at the low dose $(1.78 \mu \mathrm{g} / \mathrm{ml})$ of methanol extract, aqueous extract and ascorbic acid $29.40 \%, 27.19 \%$, and $34.38 \%$. At mid dose $(3.57 \mu \mathrm{g} / \mathrm{ml})$, methanol extract showed $35.14 \%$, aqueous extract showed $33.03 \%$ and ascorbic acid showed $38.97 \%$ of percentage inhibition. At high dose $(7.14 \mu \mathrm{g} / \mathrm{ml})$, methanol extract showed $43.26 \%$, aqueous extract showed $40.56 \%$ and ascorbic acid showed $51.04 \%$ of percentage inhibition. Data showed a non-significant increase in the percentage inhibition when both extracts at different concentrations were compared with the standard i.e. ascorbic acid.

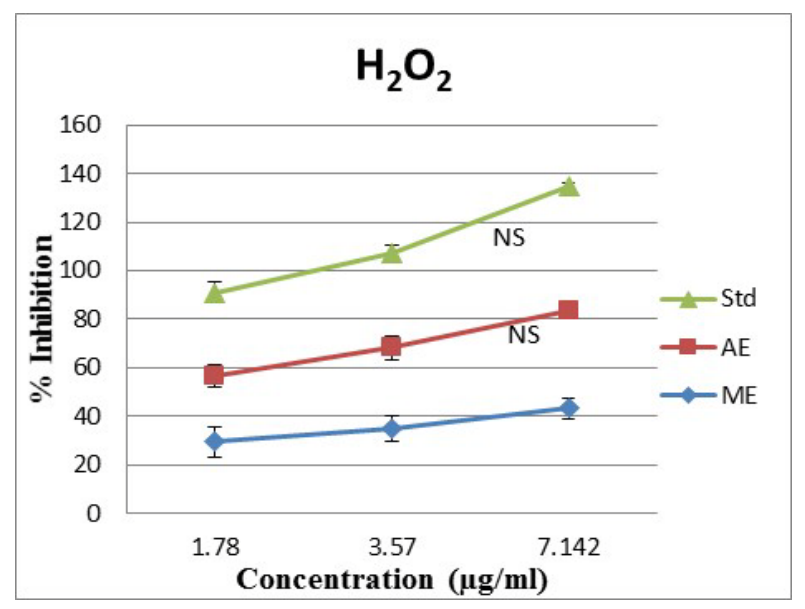

Fig. 3: Percentage inhibition of hydrogen peroxide scavenging activity of methanol extract (ME) and aqueous extract (AE) of $G$. montana in comparison with ascorbic acid (STD). Each value is represented as mean $\pm S E, n=3$ )

\section{Superoxide scavenging}

As shown in fig. 4 , at low concentration $1.78 \mu \mathrm{g} / \mathrm{ml}$, the percentage inhibition of the methanol extract was $36.44 \%$, aqueous extract was $32.29 \%$ whereas that of the standard was $38.51 \%$. At $3.57 \mu \mathrm{g} / \mathrm{ml}$ concentration methanol, aqueous and ascorbic acid showed 44.07 $\%, 41.04 \%$ and $49.11 \%$ of inhibition. At higher concentration $(7.14 \mu \mathrm{g} / \mathrm{ml})$, methanol extract and aqueous extract showed $57.86 \%$ and $46.81 \%$ inhibition. When it was compared with the ascorbic acid as a standard (63.75\%), there was a non-significant increase in the inhibition.

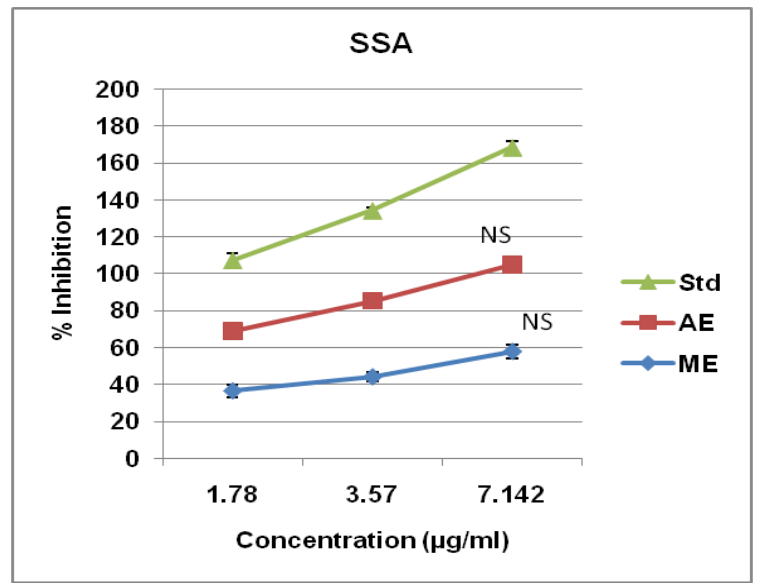

Fig. 4: Percentage inhibition of hydrogen peroxide scavenging activity of methanol extract (ME) and aqueous extract (AE) of G. montana in comparison with ascorbic acid (STD). Each value is represented as Mean $\pm S E, n=3$ ).

\section{Reducing power assay}

The antioxidant activity of both the extracts was evaluated using reduced power assay. The results of antioxidant screening are depicted in fig. 5. The present study showed that methanol and aqueous extracts showed the inhibition of $10.95 \%$ and $13.23 \%$ at 
lower concentration $(1.78 \mu \mathrm{g} / \mathrm{ml})$, whereas standard (ascorbic acid) showed $15.26 \%$. At mid dose $(3.57 \mu \mathrm{g} / \mathrm{ml})$, methanol, aqueous and ascorbic acid showed $21.04 \%, 20.44 \%$ and $27.04 \%$ of inhibition respectively. At higher concentration $(7.14 \mu \mathrm{g} / \mathrm{ml})$, methanol extract and aqueous extract showed $33 \%$ and $32 \%$ inhibition when it was compared with the standard (34\%). These results show the potential antioxidant nature of different extracts of $G$. montana at a different concentration by showing a non-significant increase in the inhibition.

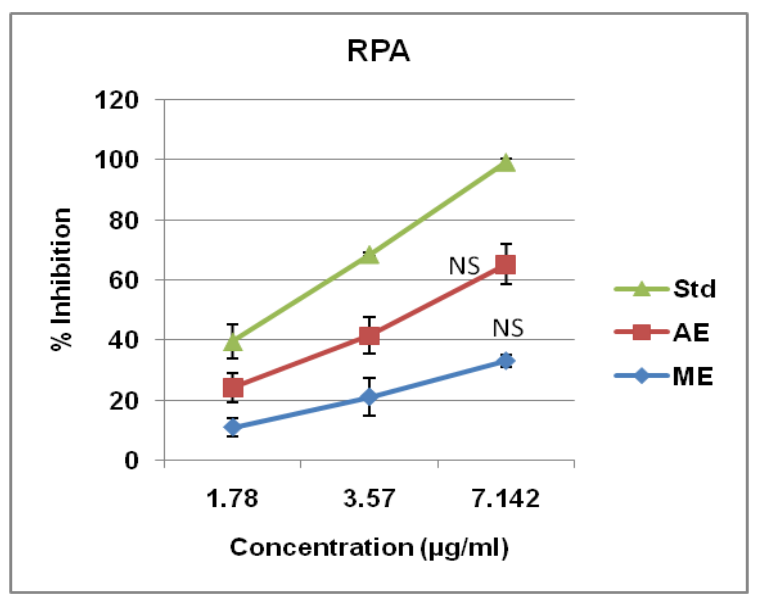

Fig. 5: Reducing the power of methanol extract (ME) and aqueous extract (AE) of $G$. montana in comparison with ascorbic acid (STD). Each value is represented as mean $\pm S E, n=3$ )

\section{DISCUSSION}

In living systems, free radicals are constantly generated, and they can cause extensive damage to tissues and bio-molecules leading to various disease conditions, especially degenerative diseases, and extensive lysis [23]. Many synthetic drugs protect against oxidative damage, but they have adverse side effects. An alternative solution to the problem is to consume natural antioxidants from food supplements and traditional medicines [24, 25]. Since ancient times, mankind has been using medicinal plants or its products to treat acute or chronic diseases as it is economical and less expensive. These medicinal plants are reported to possess diverse pharmacological applications which are attributed to the presence of phytochemicals such as phenol, alkaloids, flavonoids, glycosides, tannins, steroids, etc. Some of these plants are important sources of natural antioxidants [26] that have been shown to reduce the risk and progression of many acute and chronic diseases including cancer, cardiovascular diseases, and neurodegenerative diseases by scavenging free radicals which are implicated in the pathogenesis of these diseases [27]. Studies on medicinal plants with high phenolic contents have gained importance over the past few years due to the high antioxidant $[28,29]$, anti-inflammatory [30] and anticarcinogenic activities $[28,29]$ and are of great value in decreasing the risk of many human diseases. The anti-oxidative activities observed can be attributed to either the different mechanisms exhibited by different polyphenolic compounds that are, tocopherols, flavonoids, and other organic acids and to the synergistic effects of different compounds. Studies have shown that various polyphenols contribute significantly to the antioxidant activity [29-31] and act as highly effective free radical scavengers which are mainly due to their redox properties, which can play an important role in absorbing and neutralizing free radicals, quenching singlet and triplet oxygen or decomposing peroxides [29, 32]. Keeping this in view, two different extracts of G. montana was analyzed for the antioxidant property by using different assay in comparison with ascorbic acid, as this plant is widely used as ethnomedicine due to its hepatoprotective effect.

DPPH method is widely used in the model system to investigate the scavenging activity of several phytocompounds. The assay is based on the reduction of DPPH, a stable free radical; any molecules that can donate an electron or hydrogen to DPPH can react with it and thereby bleach the DPPH absorption. As the odd electron of the radical becomes paired off in the presence of a hydrogen donor, that is a free radical scavenging antioxidant, the absorption strength is decreased and the resulting decolorization is stoichiometric with respect to the number of electrons captured [33]. When the methanol and aqueous extracts of $G$. montana were tested for the DPPH free radical scavenging ability, the methanol extract of the leaf at higher concentration showed strong radical scavenging activity (fig. 1). One such study by Rajani et al., in the year, 2013 showed that the ethanol and methanol extracts (which are more polar solvent) were more effective antioxidants compared to the non-polar hexane extract in DPPH assay [28]. This suggests that methanol extracts contain more compounds such as polyphenolics that can donate electron/hydrogen easily. From all these observations it can be concluded that the plant extracts with a high level of phenolic compounds show excellent antioxidant activity in the in vitro systems. The aqueous extract used in the present study showed less free radical scavenging activity which might be due to their low phenolic constituents as compared to the methanol extract.

ABTS assay is based on the scavenging of light by 2, 2'-Azino-bis (3ethylbenzothiazoline-6-sulfonic acid) radicals. An antioxidant shows a marked ability to donate a hydrogen atom which would consequently quench the stable free radical. This assay is performed to evaluate the radical scavenging abilities. The methanol and aqueous leaf extract of $G$. montana were fast and effective scavengers of the ABTS radical and this activity was comparable to that of ascorbic acid. Methanol and aqueous extract exhibited potent scavenging effects against ABTS by showing greater antioxidant activities in higher concentrations than the lower concentrations, which can either be due to the presence of specific chemical compounds in the extract of $G$. montana or may be due to the pronounced contents in this extract of total phenolic content and phenolic compounds which were characterized by its great free radical scavenging, hydrogen-donating and metal chelating efficiencies. These results were in accordance with those obtained earlier in previous studies. [34-37].

The study by Gulcin, (2006) showed that hydroxyl radicals are highly potent oxidants, which can react with biomolecules in living cells and cause severe damage [38]. The permeability of hydrogen peroxide across the cell membranes is considered a reason for the toxicity of this weak oxidizing agent [39]. The present study revealed that the leaf extracts of $G$. montana react with the hydroxyl radicals, thus acts as a potent natural antioxidant and would prevent the cellular damage. Some investigations showed that phytochemical constituents such as flavonoids and other phenolic compounds have multiple biological effects such as antioxidant activity, antiinflammatory actions, inhibition of platelets aggregation and antimicrobial activities [40]. The most likely mechanism of antioxidant protection is direct interaction of the extract (or compounds) and the hydrogen peroxide rather than altering the cell membranes and limiting damage [41]. Compounds with high radicalscavenging capacity have shown to facilitate wound healing. Hydrogen peroxide is a weak oxidizing agent that inactivates a few enzymes directly, usually by oxidation of essential thiol $(-\mathrm{SH})$ groups. It can cross cell membranes rapidly; once inside the cell, it can probably react with $\mathrm{Fe}^{2+}$ and possibly $\mathrm{Cu}^{2+}$ ions to form hydroxyl radicals and this may be the origin of many of its toxic effects [42]. In the present study, the administration of both the leaf extracts to the reaction mixture inhibited the hydroxyl radical activity in a dosedependent manner. The standard showed-significant higher inhibition compared to both the extracts, which proves their concentration-dependent $\mathrm{H}_{2} \mathrm{O}_{2}$ scavenging activity.

The superoxide scavenging activity of $G$. montana was investigated because the extract has the potential to scavenge superoxide anions. Fig. 4 clearly indicates that G. montana is a potent scavenger of superoxide radicals. The superoxide radicals generated from dissolved oxygen by PMS-NADH coupling can be measured by their ability to reduce NBT. The decrease in absorbance at $560 \mathrm{~nm}$ with the plant extract and the standard indicates their abilities to quench superoxide radicals in the reaction mixture. As shown in fig. 4 , at higher concentration, aqueous extract showed lesser percentage 
inhibition than methanol extract when it was compared with the ascorbic acid as a standard indicating methanol extract scavenge more superoxides as compared to aqueous extract. Similar studies reported that Superoxide radical is considered a major biological source of reactive oxygen species [43]. Although superoxide anion is a weak oxidant, it gives rise to a generation of powerful and dangerous hydroxyl radicals as well as singlet oxygen, both of which contribute to oxidative stress [44].

Since the reducing power activity of the compounds could serve as a significant indicator of the antioxidant potential, we assessed this property by measuring the ability of the extracts to transform $\mathrm{Fe}^{3+}$ to $\mathrm{Fe}^{2+}$ and to donate an electron [45]. Reducing the power of a compound acts as an indicator of its potential antioxidant activity [46]. This study showed that G. montana had comparable reducing power with ascorbic acid. Reducing the power of both the extracts performed at different concentrations showed dose-dependent reducing activity and methanol extract proved to have a better reducing power ability amongst both the extracts. The results of antioxidant screening are depicted in fig. 5 . The present study showed that methanol and aqueous extracts showed lesser inhibition at lower concentration $(1.78 \mu \mathrm{g} / \mathrm{ml})$ than standard (ascorbic acid). Here, methanol extract showed less inhibition at the lower concentration than aqueous extract, whereas, at higher doses, both the extracts showed a similar amount of percent inhibition, when they were compared with ascorbic acid. These results show the potential antioxidant nature of both the extracts of $G$. montana at a different concentration by showing a non-significant increase in the inhibition in a dose-dependent manner (fig. 5). Similar studies, which showed the ability of the extracts to reduce $\mathrm{Fe}^{3+}{ }^{3+}$ could be attributed either to the reducing agents such as phenol groups and the number or/and the position of the hydroxyl molecule on these groups [47]. Radial scavenging and antioxidant potential of leaves were ascribed to its phenolic and flavonoid content as described in previous studies by Kanase and Mane (2018) [48].

Antioxidant activity has been reported to increase proportionally to the polyphenol content as it is responsible for the radical scavenging effects mainly due to its redox properties [49]. Thus, this study confirmed that $G$. montana plant is a good source of antioxidants and it should be further investigated for genotoxicity and cytotoxicity before its use in medical science.

\section{CONCLUSION}

In the present study, two different extracts (methanol and aqueous) of G. montana were tested at three doses with respect to their antioxidant capacity and oxidative stability. The antioxidant capacity was measured by the free radical scavenging methods DPPH, ABTS $\mathrm{H}_{2} \mathrm{O}_{2}$, superoxide scavenging and reducing power ability. This study revealed that the methanol extract showed a higher antioxidant capacity as compared to aqueous extract proved by their lower IC ${ }_{50}$ concentration. At different concentrations, percentage inhibition by different methods showed the minor difference between the two extracts in a dose-dependent non-significant manner when they were compared with the standard. The results demonstrated that the extracts of $G$. montana possess antioxidant properties and could serve as free radical inhibitors or scavengers or act as a primary antioxidant. With this kind of investigation, it would be easier to treat and prevent human damages occurring due to the free radical. Therefore, further research is needed for the isolation and identification of the active components in the extracts and extensive investigation needs to be done to determine the in vitro or in vivo biological activity of these extracts before its wider acceptance as antioxidants.

\section{ACKNOWLEDGMENT}

This study was supported by the Maulana Azad National Fellowship (MANF) grant from the University Grants Commission (UGC).

\section{AUTHORS CONTRIBUTIONS}

Dr. Divya Chandel designed the experiment and drafted and revised the manuscript. Ms. Nishat Ansari has performed the experiments and wrote and revised the manuscript.

\section{CONFLICT OF INTERESTS}

Declared none

\section{REFERENCES}

1. Sen S, Chakraborty R, Sridhar C, Reddy YSR, De B. Free radicals, antioxidants, diseases, and phytomedicines: current status and future prospect. Int J Pharm Sci Res 2010;3:91-100.

2. Droge W. Free radicals in the physiological control of cell function. Physiol Rev 2002;82:47-95.

3. Sharma S, Nagpal A, Vig AP. The genoprotective potential of brassica juncea czern against mercury-induced Genotoxicity in Allium cepa L. Turk J Biol 2012;36:622-9.

4. Nahak G, Sahu RK. Phytochemical evaluation and antioxidant activity of Piper cubeba and Piper nigrum. J Appl Pharm Sci 2011;1:153-7.

5. Cotelle N, Bernier JL, Catteau JP, Pommery J, Wallet JC, Gaydou EM. Anti-oxidant properties of hydroxy-flavones. Free Radical Biol Med 1996;20:35-43.

6. Mitscher LA, Telikepalli H, Mc Ghee E, Shankel DM. Natural antimutagenic agents. Mutat Res 1996;350:142-3.

7. Owen RW, Giacosa A, Hull WE, Haubner R, Spiegelhalder B, Bartsch H. The antioxidant/anticancer potential of phenolic compounds isolated from olive oil. Eur J Cancer 2000;36:1235-47.

8. Sala A, Recio M, Giner RM, Manez S, Tournier H, Schinella G, et al. Anti-inflammatory and antioxidant properties of Helichrysum italicum. J Pharm Pharmacol 2002;54:365-71.

9. Cai $Y$, Luo $Q$, Sun M, Corke H. Antioxidant activity and phenolic compounds of 112 traditional chinese medicinal plants associated with anticancer. Life Sci 2004;74:2157-84.

10. Sabeeha S, Nahida T. Phytochemical screening and renal effects of ethanolic extract of Eriobotrya japonica fruits and seeds in alloxaninduced diabetic rats. Int J Curr Pharm Res 2017;10:3-7.

11. Maruthamuthu R, Maithili V, Arunazhagi R, Yogesh V. Phytochemical profiling of medically significant crude extract using GC-ms analysis. Int J Curr Pharm Res 2018;10:16-20.

12. Cao G, Sofic ER, Prior RL. Antioxidant capacity of tea and common vegetables. J Agric. Food Chem 1996;44:3426-31.

13. Aiyegoro OA, Okoh AI. Preliminary phytochemical screening and in vitro antioxidant activities of the aqueous extract of Helichrysum longifolium DC. BMC Complement Altern Med 2010;10:1-8.

14. Sarkar D, Sharma A, Talukder G. Plant extract as modulators of genotoxic effects. Bot Rev 2008;62:275-300.

15. Bhavita D, Lakshmi B, Maitreyi Z. An overview on ethnomedicinal plant Gymnosporia montana of celastraceae family. Int J Pharm Chem Med 2017;1:1-5.

16. Raikar AN, Nagashree PS, Sinchana CV, Swathi BB, Prashith KT, Raghavendra HL. Antimicrobial and radical scavenging activity of Gymnosporia montana (Roth.) benth. World J Pharm Pharm Sci 2015;4:1940-8.

17. Dhru B, Zaveri M, Lakshmi B. Pharmacognostical and phytochemical study of the leaf of Gymnosporia montana (vikalo). J Glob Pharma Tech 2011;3:23-7.

18. Goze I, Alim A, Tepe AS, Sokmen M, Sevgi K, Tepe B. Screening of the antioxidant activity of essential oil and various extracts of Origanum rotundifolium Boiss. from Turkey. J Med Plants Res 2009;3:246-54.

19. Re R, Pellegrini N, Proteggente A, Pannala A, Yang M, Rice Evans C. Antioxidant activity applying an improved ABTS radical cation decolorization assay. Free Radical Biol Med 1999;26:1231-7.

20. Ruch RJ, Cheng SJ, Klaunig JE. Prevention of cytotoxicity and inhibition of intercellular communication by antioxidant catechins isolated from chinese green tea. Carcinogenesis 1989;10:1003-8.

21. Fontana M, Mosca L, Rosie M. Interaction of enkephalins with oxyradicals. Biochem Pharmacol 2001;61:1253-7.

22. M Oyaizu. Studies on product of browning reaction prepared from glucose amine. Japan J Nutr Diet 1986;44:307-15.

23. Halliwell B, Gutteridge JM. Free radicals in bio and med Oxford: Clarendon Press; $3^{\text {rd }}$ ed. New York: Oxford University Press; 1999. 
24. Yazdanparast $\mathrm{R}$, Ardestani A. In vitro antioxidant and free radical scavenging activity of Cyperus rotundas. J Med Food 2007;10:667-74.

25. Yazdanparast R, Bahramikias S, Ardestani A. Nasturtium officinale reduces oxidative stress and enhances antioxidant capacity in hypercholesterolemic rats. Chem Biol Interact 2008;172:176-84

26. Rice Evans C. Flavonoids and isoflavones: absorption, metabolism, and bioactivity. Free Radical Biol Med 2004;36:827-8

27. Kumar H, Lim HW, More SV, Kim BW, Koppula S, Kim IS, et al. The role of free radicals in the aging brain and Parkinson's disease: convergence and parallelism. Int $\mathrm{J}$ Mol Sci 2012;13:10478-504.

28. Zakaria ZA, Rofiee MS, The LK, Salleh MZ, Sulaiman MR, Somchit MN. Bauhinia purpurea leaves extracts exhibited in vitro antiproliferative and antioxidant activities. Afr J Biotechnol 2011;10:65-74

29. Rajani KS, Manoranjan K, Rasmirani R. DPPH free radical scavenging activity of some leafy vegetables used by tribals of Odisha, India. J Med Plants Stud 2013;1:21-7.

30. Kim HP, Son KH, Chang HW, Kang SS. Antiinflammatory plant flavonoids and cellular action mechanisms. J Pharmacol Sci 2004;96:229-45.

31. Demian, Verma H. In vitro antioxidant activity, total phenolic and total flavonoid content of different extracts of solanum xanthocarpum Berries. Int J Pharm Pharm Sci 2012;4:154-7.

32. Hasan SM, Hossain MM, Faruque A, Majumdar MEH, Rana MS Akter R, et al. Comparison of antioxidant potential of different fractions of Commelina benghalensis Linn. Bangladesh J Life Sci 2008;20:9-16.

33. Blois MS. antioxidant determinations by the use of a stable. Free Radical Nat 1958;181:1199-200.

34. Cook NC, Samman S. Flavonoids-chemistry, metabolism, cardioprotective effects, and dietary sources. J Nutr Biochem 1996; 7:66-76.

35. Sroka Z. The screening analysis of the antiradical activity of some plant extracts. Postepy Hig Med Dosw 2006;60:563-70.

36. Vogrincic M, Timoracka M, Melichacova S, Vollmannova A, Kreft I. Degradation of rutin and polyphenols during the preparation of Tartary buckwheat bread. J Agric Food Chem 2010;58:4883-7.
37. Emad AS, Sanaa MM. Comparison of DPPH and ABTS assay for determining `antioxidant potential of water and methanol extracts of Spirulina platensis. Ind J Geo Marine Sci 2013; 42:556-64.

38. Gulcin I. Antioxidant and antiradical activities of L-carnitine. Life Sci 2006;78:803-11.

39. Suriya K, Rema R, Philip RJ. Antioxidant and cytotoxic activity of combined extracts prepared using ficus religiosa and ficus benghalensis leaves against the cervical cancer cell line (hela). Asian J Pharm Clin Res 2018;11:407-10.

40. Venkatanarayana D, Saravana K, Mohana S, Lakshmi. Review on natural wound healing Agents. Int J Phytopharm Res 2010;1:1-4

41. Annan K, Houghton P. Antibacterial, antioxidant and fibroblast growth stimulation of aqueous extracts of Ficus asperifolia and Gossypium arboretum, wound-healing plants of Ghana. J Ethnopharmacol 2008;119:141-4.

42. Kumaran A, Karunakaran RJ. In vitro antioxidant activities of methanolic extract of phyllanthus species from India. LWT Food Sci Technol 2008;40:322-52.

43. Alves CQ, David JM, David JP, Bahia MV, Aguiar RM. Methods for determination of in vitro antioxidant activity for extracts and organic compounds. Quim Nova 2010;33:2202-10.

44. Meyer AS, Isaksen A. Application of enzymes as food antioxidants. Trends Food Sci Tech 1995;6:300-4

45. Rao AS, Reddy SG, Babu PP, Reddy AR. The antioxidant and antiproliferative activities of methanolic extracts from Njavara rice bran. BMC Complement Altern Med 2010;10:4.

46. Meir S, Kanner J, Akiri B. Determination and involvement of aqueous reducing compounds in the oxidative defense system of various senescing leaves. J Agric Food Chem 1995;43:1813-9.

47. Joseph GP. Beta-lactamase characterization and their inhibition by medicinal plants extract. Belgium: University de Liège; French; 2007. Available from: http://bictel.ulg.ac.be/ETD$\mathrm{db} /$ collection/available/ULgetd-10172007-110129.

48. Kanase V, Mane D. A pharmacognostic and pharmacological review on alstonia scholaris. Asian J Pharm Clin Res 2018;11:22-6.

49. Adedapo AA, Jimoh FO, Koduru S, Afolayan AJ, Masika PJ. Antibacterial and antioxidant properties of the methanol extracts of the leaves and stems of Calpurnia aurea. BMC Complement Altern Med 2008;8:53. 